\title{
Revista Contexto GENGRÁFICO

\section{ANÁLISE DA DISPERSÃO ESTIMADA DE COLIFORMES TERMOTOLERANTES PARA OS PERÍODOS DE INVERNO E VERÃO NA LAGUNA MUNDAÚ, ALAGOAS}

Esdras de Lima Andrade

Universidade Federal de Alagoas, Instituto de Geografia, Desenvolvimento e Meio Ambiente,

Maceió, AL, Brasil

esdras.andrade@,igdema.ufal.br

\author{
Alex Nazário Silva Oliveira \\ Universidade Federal de Alagoas, Instituto de Geografia, Desenvolvimento e Meio Ambiente, \\ Maceió, AL, Brasil \\ alexnazario@hotmail.com
}

Sinval Autran Mendes Guimarães Júnior

Universidade Federal de Alagoas, Instituto de Geografia, Desenvolvimento e Meio Ambiente,

Maceió, AL, Brasil

sinval.autran@igdema.ufal.br

\begin{abstract}
RESUMO - Este trabalho teve como objetivo principal estimar o comportamento da distribuição espacial de coliformes termotolerantes na laguna Mundaú, entre os meses de junho e dezembro de 2007, utilizando exclusivamente o software livre Quantum GIS 1.4. A metodologia adotada concentrou-se basicamente na obtenção e geração da base de dados e na interpolação dos valores das amostras por meio do algoritmo do Inverso da Distância à Potência. As amostras foram obtidas em diferentes momentos, sendo a primeira campanha realizada em junho e a segunda em dezembro de 2007, ambas sem ocorrência de chuva nas últimas 24 horas. Assim, a partir dos resultados e das análises bacteriológicas, observaram-se concentrações consideráveis de coliformes termotolerantes nas coleções realizadas nos dois períodos analisados. No entanto, com base na resolução CONAMA $\mathrm{n}^{\circ}$. 274/2000, verificou-se que apenas as águas relativas ao mês de junho são inadequadas para o banho, com concentrações de coliformes fecais aproximadamente 6,5 vezes maiores do que o valor permitido. Por outro lado, os resultados alcançados no mês de dezembro foram considerados satisfatórios, com concentrações inferiores a 900 coliformes por 100 mililitros.
\end{abstract}

Palavras-chave: Balneabilidade, Impacto Ambiental, Geoprocessamento, Interpolação.

\section{ANALYSIS OF THE ESTIMATED DISPERSION OF THERMOTOLERANT COLIFORMS FOR THE WINTER AND SUMMER PERIODS IN THE MUNDAÚ LAGOON, ALAGOAS}

\begin{abstract}
This paper had as main objective to esteem the behavior of the space distribution of thermotolerant coliforms in the lagoon Mundaú, between the months of June and December of 2007, exclusively using free software Quantum GIS 1.4. The adopted methodology concentrates on obtaining and generating database and in the interpolation of the samples values by means of the Inverse of the Distance to the Potency algorithm. The samples were obtained in different times, being the first campaign accomplished in June and Monday in December 2007, both without rain occurrence in the last 24 hours. Thus, starting from the results and of the bacteriological analyses considerable concentrations of thermotolerant coliforms were observed in the collections accomplished in the both analyzed periods. However, with base in the CONAMA's resolution number $274 / 2000$, it was verified that only the relative waters to the month of June are inappropriate for bathing, with fecal coliform concentrations approximately 6.5 larger times than the allowed value. On the other hand, the results reached in the month of December were considered satisfactory, with less concentrations to 900 coliforms for 100 milliliters.
\end{abstract}

Keywords: Bathing, Environmental Impact, Geoprocessing, Interpolation. 


\section{INTRODUÇÃO}

A Laguna Mundaú pode ser considerada a mais importante do estado de Alagoas, não só pelos fatores históricos e paisagísticos, mas, principalmente, pela sua localização geográfica, que recebe influências demográficas e socioeconômica diretamente da capital alagoana. De acordo com o censo do IBGE referente ao ano de 2000, residiam no entorno da laguna 314.296 pessoas, distribuídas em 18 bairros da cidade de Maceió, com 267.353 habitantes e 4 cidades que integram a região metropolitana de Maceió (Santa Luzia do Norte, Coqueiro Seco, Satuba e Marechal Deodoro), com 46.943 habitantes. Estima-se que aproximadamente dez por cento desta população tira o seu sustento diretamente deste corpo hídrico.

Algumas evidências indicam que a referida laguna vem sofrendo, nas últimas três décadas, variados e intensos impactos ambientais em seu leito e margens, e estão diretamente relacionadas às tipologias de uso e ocupação do solo no seu entorno.

Desta forma, como a margem esquerda está ocupada predominantemente pela área urbana de Maceió, com destaque para a grande incidência de ocupações subnormais, verifica-se a ausência de sistema de saneamento básico, que contribui, em parte, com o lançamento dos efluentes residenciais no interior da laguna, ajudando a comprometer a qualidade da água. Já a margem direita, nas cotas mais baixas, o uso agrícola é predominantemente, com destaque às culturas do coco-da-baía (Cocos nucifera) e da cana-de-açúcar (Saccharum officinarum), e dois pequenos núcleos urbanos, que correspondem as cidades de Santa Luzia do Norte e de Coqueiro Seco.

Além dos impactos mencionados, estão relacionados ainda a esses usos e ocupações o forte processo de assoreamento; a eutrofização; o desaparecimento de espécies da fauna aquática; a recorrência de mortandades de peixes e a contaminação por coliformes, organismos patogênicos, pesticidas e metais.

Apesar desses problemas, a laguna cumpre ainda outro papel, funcionando como uma espécie de corredor ecológico aquático entre as Áreas de Proteção Ambiental (APAs) de Santa Rita, ao sul e do Catolé e Fernão Velho, ao norte.

Como o principal objetivo deste trabalho foi realizar uma análise do comportamento espacial da variável "coliformes termotolerantes" nos meses de junho e dezembro de 2007, buscou-se aplicar a técnica geoestatística de interpolação, estruturada em ambiente SIG (Sistema de Informações Geográficas).

Desta forma, o presente trabalho apresenta a espacialização da variável coliformes termotolerantes na laguna Mundaú.

Esses coliformes pertencem ao grupo das bactérias que têm origem predominante no trato intestinal de animais de sangue quente, tendo o gênero Escherichia o mais abundante, e, devido a sua origem, é majoritariamente encontrada em esgotos, efluentes tratados e águas naturais sujeitas a contaminação por atividades agropecuárias (WHO, 1993).

Devido a esta predominância e às propriedades solventes da água e às suas capacidades de transportar partículas e de incorporar impurezas, esta bactéria é adotada como bioindicador de qualidade da água, para fins de balneabilidade (VON SPERLING, 2005) e cultivo de moluscos bivalves (BRASIL, 2005).

Nesse contexto, a avaliação da qualidade da água para esse indicador, passa pela análise probabilística de proporcionarem risco de transmissão de doenças infecciosas através do contato direto com a água contaminada. Nesse entendimento, a Resolução Conama $n^{\circ}$. 274/2000 estabelece que as águas salobras de classe 1 são consideradas impróprias para recreação quando, no trecho avaliado, o valor obtido, ou seja, o número mais provável (NMP) na última 
amostragem, seja superior a 2.500 coliformes para cada 100 mililitros de água. Para fins de cultivo de moluscos bivalves, a resolução Conama $\mathrm{n}^{\circ}$. 357/2005 estabelece que o valor admitido do NMP é de no máximo 43 para cada $100 \mathrm{ml}$ de água.

Assim, para espacializar os valores correspondentes a esta variável, recorreu-se à geoestatística pois, devido a sua natureza, se diferencia da estatística clássica, já que lida com variáveis regionalizadas, ou seja, á aplicada aos fenômenos que têm ocorrência e variam no espaço (LANDIM, 1998; OLEA, 1991).

Nesse sentido, a estimativa espacial dos coliformes termotolerantes na laguna Mundaú passa pelo entendimento do seu comportamento em uma superfície contínua a partir de um conjunto finito de dados amostrados pontualmente neste meio, modelando um padrão espacial desses dados (CORREIA, 2010).

Em outras palavras, isso se traduz na adoção de métodos de interpolação, o qual estima a distribuição espacial de uma dada superfície, baseado em alguns valores conhecidos, devidamente geolocalizados.

Dentre os modelos mais usados está o Inverso da Distância Ponderada - IDP (Inverse Distance Weighting - IDW). Nele, o modelo estatístico, que é denominado Inverso das Distâncias, se baseia na dependência espacial. Isto significa que, quanto mais próximo um ponto estiver do outro, maior será sua correlação entre seus valores, ou seja, mais parecidos esses valores serão e, quanto mais distantes, menos parecidos serão.

Nisso, Varella e Sena Junior (2008) explicam que o interpolador

[...] atribui maior peso para as amostras mais próximas do que para as amostras mais distantes do ponto a ser interpolado. Assim o modelo consiste em se multiplicar os valores das amostras pelo inverso das suas respectivas distâncias ao ponto de referência para a interpolação dos valores.

\section{ÁREA DE ESTUDO}

Localizada na porção central do litoral do estado de Alagoas, a laguna Mundaú se situa entre as coordenadas geográficas $9^{\circ} 43^{\prime} 19^{\prime \prime}$ e $9^{\circ} 35^{\prime} 13^{\prime \prime}$ de latitude sul e $35^{\circ} 48^{\prime} 24^{\prime \prime}$ e $35^{\circ} 45^{\prime} 03^{\prime \prime}$ de longitude oeste, estendendo-se por uma área de aproximadamente $27 \mathrm{~km}^{2} \mathrm{em}$ um perímetro de $28.996 \mathrm{~m}$, sendo seu comprimento de 7,7 km e largura variando entre 2,6 $\mathrm{km}$ (montante) a 4,6 km (jusante); abrange parte dos municípios de Maceió, Marechal Deodoro, Coqueiro Seco e Santa Luzia do Norte.

Interliga-se com o Oceano Atlântico através de uma extensa rede de canais que corta a planície formando dezenas de pequenas ilhas. Sua profundidade varia dos 2 aos 7 metros, sendo a sua profundidade média de 1,5 m (ALAGOAS, 1988). Na região dos canais a profundidade média é de 1,9 m. O solo, no leito desta Laguna apresenta vaza e depósitos de fragmentos de conchas de moluscos, carapaças de crustáceos e argila síltica. 
Figura1 - Localização da área de estudo.

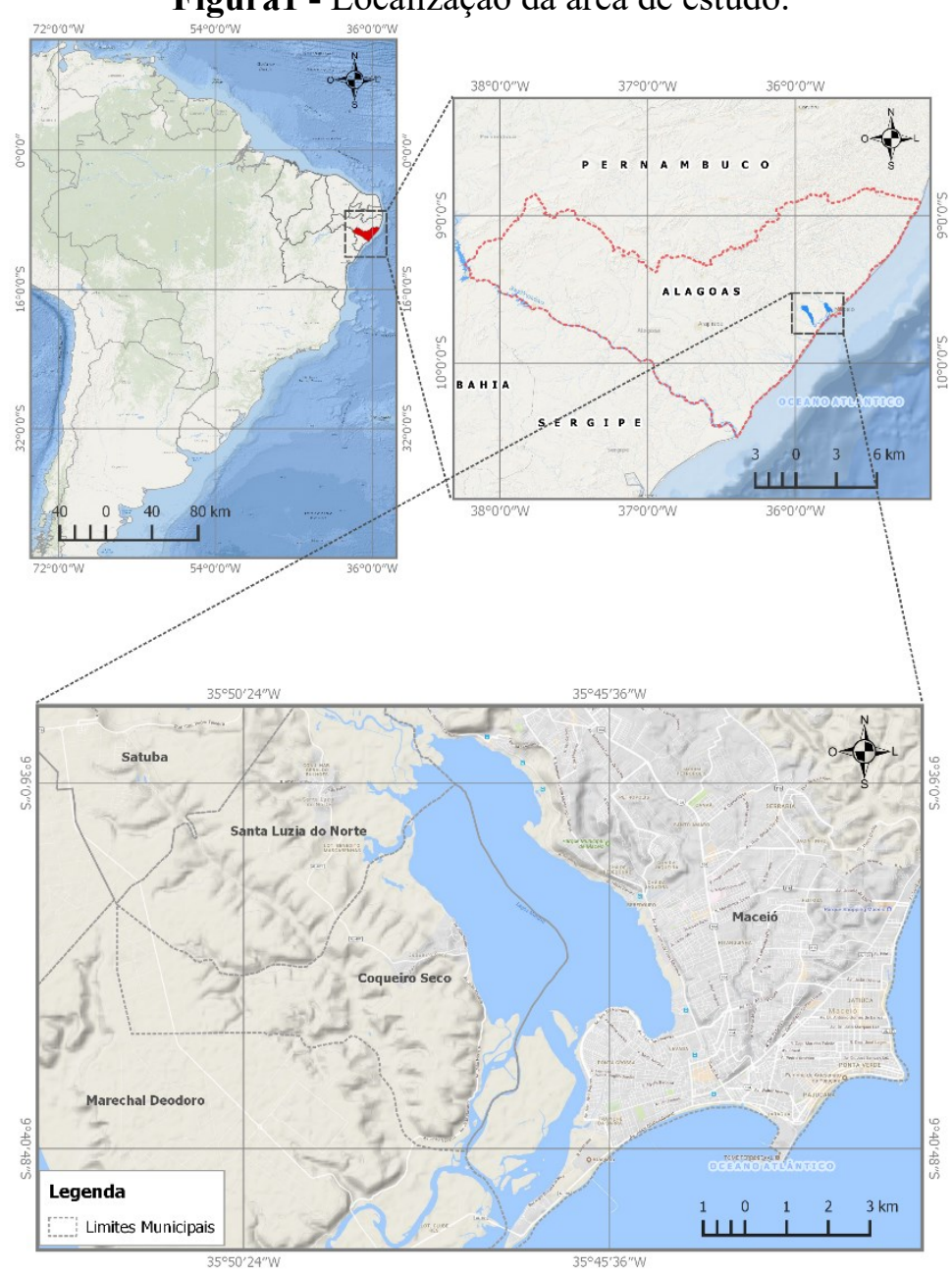

\section{PROCEDIMENTOS METODOLÓGICOS}

Os procedimentos metodológicos adotados se concentraram basicamente na obtenção e geração da base de dados e da modelagem da estimativa espacial.

Os meses selecionados para realização das coletas são justificados por serem historicamente os que apresentam, respectivamente, maior e menor precipitação na região onde se insere a área estudada.

\section{Obtenção dos Dados}

Os dados foram obtidos através de duas coletas com amostragens em épocas distintas, sendo a primeira no dia 13 de junho e a segunda no dia 11 de dezembro, ambas no ano de 2007 e sem ocorrência de chuva nas 24 horas anteriores. Os procedimentos foram realizados pelos técnicos da Diretoria de Laboratórios do Instituto do Meio Ambiente de Alagoas (DILABIMA); sendo em seguida conduzidos para análises. As amostragens foram realizadas nas imediações dos postos de coleta, definidos pela Cetesb que efetuou estudo entre os anos de 1984 e 1985, e são apresentadas na Tabela 1. 
Tabela 1 - Coordenadas UTM dos postos de coleta das amostras de coliformes termotolerantes.

\begin{tabular}{ccc}
\hline Postos de Coleta & Longitude Este & Latitude Norte \\
\hline 1 & 194071 & 8937726 \\
2 & 195237 & 8933884 \\
3 & 193882 & 8933504 \\
4 & 198210 & 8931654 \\
5 & 196398 & 8931672 \\
6 & 193404 & 8928570 \\
7 & 192275 & 8924744 \\
8 & 196161 & 8928885 \\
9 & 190993 & 8927118 \\
10 & 191176 & 8927284 \\
11 & 192160 & 8924286 \\
\hline
\end{tabular}

\section{Geração da Base de Dados}

A base de dados foi elaborada a partir das imagens de satélite Quickbird, sensor QB02, banda Pan MS1, com resolução espacial de 0,60 m, registrada em 20 de dezembro de 2009, através do qual foram vetorizadas, no software QGIS 1.4, as feições dos corpos d'água, ilhas e porção continental adjacente à área de estudo.

\section{Modelagem da Estimativa Espacial}

A escolha do interpolador IDW baseou-se nas considerações de Landim (2000) que, ressalta a fidelidade deste modelo aos valores originais amostrados, principalmente em situações onde há poucas amostras e com espaçamento irregular, propiciando um resultado final que se aproxima da realidade local e, porque não extrapola os valores mínimos e máximos das amostras coletadas, assemelhando-se ao interpolador Krigagem; sendo ideal para os casos onde não há agrupamento das amostras.

\section{Análise estatística}

A partir dos relatórios de análise bacteriológicos foram obtidas as concentrações de coliforme termotolerantes para as campanhas de coletas realizadas durantes os meses de junho e dezembro de 2007 (Tabela 2).

Tabela 2 - Contagem do NMP coliformes termotolerantes para os meses de jun. e dez. de 2007.

\begin{tabular}{ccc}
\hline \multirow{2}{*}{ Pontos } & \multicolumn{2}{c}{ NMP Coliformes Termotolerantes/100ml } \\
\cline { 2 - 3 } & Junho & Dezembro \\
\hline 1 & 800 & 70 \\
2 & 40 & 20 \\
3 & 230 & 20 \\
4 & 16.000 & 230 \\
5 & 5.000 & 80 \\
6 & 230 & 0 \\
7 & 80 & 130 \\
8 & 5.000 & 900 \\
9 & 170 & 220 \\
10 & 900 & 140 \\
11 & 0 & 0 \\
\hline
\end{tabular}


A fim de entender o comportamento espacial dos coliformes termotolerantes na laguna Mundaú, foram realizadas análises estatísticas descritivas que deram subsídios para a avaliação da dispersão na área em questão.

Com base nesses valores, pôde-se observar, conforme Tabela 3, que a variável em apreço apresentou, nas duas campanhas, coeficientes de assimetria bem próximos, com uma distribuição assimétrica positiva pois os valores das médias superam os das medianas e das modas, atestando o afastamento entre as grandezas extremas da série amostrada.

Tabela 3 - Resultado das estatísticas descritivas para a variável coliformes termotolerantes.

\begin{tabular}{lcc}
\hline \multicolumn{1}{c}{ Estatísticas } & Junho 2007 & Dezembro 2007 \\
\hline Número de amostras & 11 & 11 \\
Mínimo & 0 & 0 \\
Máximo & 16.000 & 900 \\
Média & $2.586,36$ & 164,55 \\
Mediana & 230 & 80 \\
Moda & 230 & 20 \\
Desvio padrão & $4.837,46$ & 257,31 \\
Variância da amostra & $23.401 .065,45$ & $66.207,27$ \\
Coeficiente de curtose & 6,77 & 8,17 \\
Coeficiente de variação (\%) & 1,87 & 1,56 \\
Coeficiente de assimetria & 2,53 & 2,74 \\
\hline
\end{tabular}

Em relação aos coeficientes de variação, para ambos períodos, a dispersão dos valores se mostrou equivalente, no entanto, os dados relativos ao mês de dezembro mostram que são levemente mais homogêneos do que os de junho, indicando que há menos variabilidade no conjunto dos dados.

\section{RESULTADOS E DISCUSSÃO}

Os valores encontrados nos dois períodos estudados se apresentam em amplitudes díspares, principalmente nos dois pontos onde há as maiores concentrações de coliformes. Referem-se aos postos de coletas 4 (Figura 2) e 8 (Figura 3). No primeiro, a amplitude é de 15.770; passando dos $16.000 \mathrm{NMP} / 100 \mathrm{ml}$ no mês de junho para $230 \mathrm{NMP} / 100 \mathrm{ml}$ no mês de dezembro. No segundo caso, a amplitude é de $4.100 \mathrm{NMP} / 100 \mathrm{ml}$; indo de $5.000 \mathrm{NMP} / 100 \mathrm{ml}$ para 900 $\mathrm{NMP} / 100 \mathrm{ml}$.

O posto de coleta número 4 corresponde a desembocadura do canal da Levada, conta com a presença de aglomerações subnormais nesta parte da margem da laguna Mundaú, pelo qual despeja parte do esgoto dos bairros do Prado, Ponta Grossa, Levada e Centro. Convém mencionar que este canal sofre influência direta do Mercado Público Municipal (Mercado da Produção) e da Central de Abastecimento de Alagoas (Ceasa), e que nos seus arredores, existem diversas pocilgas clandestinas que lançam os dejetos animais tanto em vias públicas quanto no Canal da Levada.

Já o posto de coleta número 8 corresponde a desembocadura do canal da Assembleia, no bairro Trapiche da Barra. Nesta localidade, também se verifica a presença de aglomerações 
subnormais, no qual despeja parte do esgoto dos bairros do Prado, Ponta Grossa, Trapiche e Pontal da Barra.

Figura 2 - Estimativa da dispersão espacial para o mês de junho de 2007 .

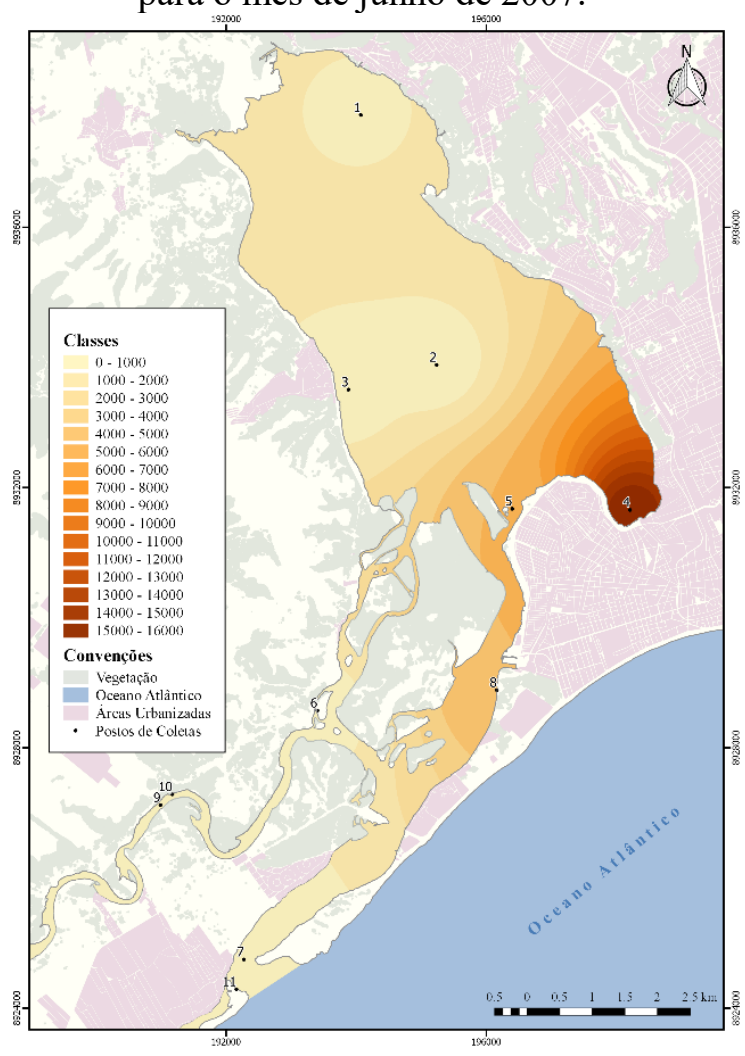

Figura 3 - Estimativa da dispersão espacial para o mês de dezembro de 2007.

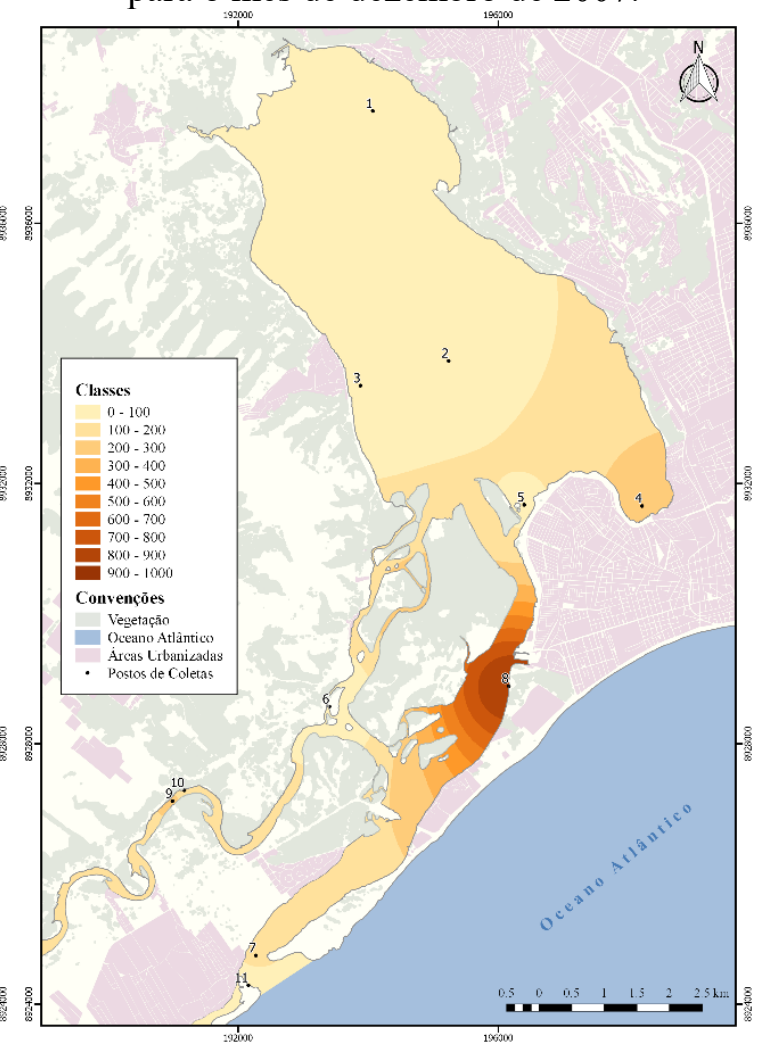

Ao realizar o cotejo entre os postos de coletas destacados para as duas datas é possível constatar à luz das resoluções Conama $n^{\circ}$. 274/2000 e $\mathrm{n}^{\circ}$. 357/2005 que, os números mais prováveis de coliformes termotolerantes são considerados extremamente impróprias tanto à balneabilidade quanto ao cultivo do sururu durante a estação chuvosa em ambos postos. No entanto, quando se trata da estação seca, a balneabilidade passa para níveis aceitáveis, mas para a criação do molusco os valores continuam em desacordo com a aludida resolução.

Em relação ao deslocamento geográfico da concentração dos maiores valores de NMP de coliformes, este, move-se do bairro Levada (posto 4) para o bairro Trapiche da Barra (posto 8) e está associado ao sistema de circulação das águas na laguna que, por sua vez, sofre influência direta de fatores como chuvas, ventos, marés e batimetria.

De acordo com Alagoas (2009), os dados do Monitoramento Climático da Secretaria de Estado do Meio Ambiente e dos Recursos Hídricos de Alagoas - SEMARH para o mês de junho mostra uma densidade pluviométrica média de $265 \mathrm{~mm}$, sendo registrado para o dia da coleta, uma precipitação de apenas $4 \mathrm{~mm}$ nas adjacências da área estudada (Figura 4). Para o mês de dezembro esta mesma densidade foi de $36 \mathrm{~mm}$ e para o dia da coleta a precipitação registrada foi de $5 \mathrm{~mm}$ (Figura 5). 
Figura 4 - Precipitação diária para os meses de junho e dezembro de 2007.

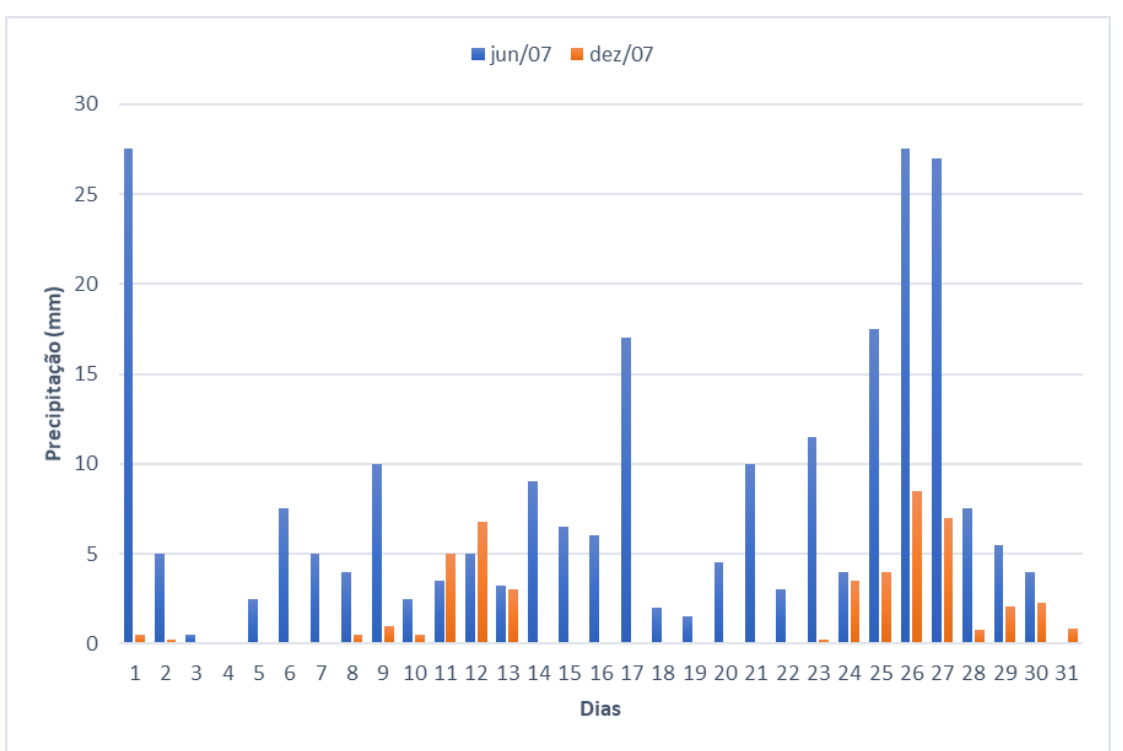

Fonte: Alagoas (2009).

Historicamente, junho apresenta a maior quantidade de chuvas do ano na região, o que propicia um volume maior de descarga tanto das águas fluviais quanto das pluviais desta porção dos bairros da capital alagoana, amplificando a quantidade de coliformes diluída na água.

As galerias pluviais recebem esta incumbência de lançar coliformes na laguna Mundaú porque ainda estão associadas à admissão dos esgotos residenciais, mesmo já existindo uma estação de coleta e tratamento interligado ao emissário submarino da região. $\mathrm{O}$ fato é que grande parte do sistema ainda se encontra inativo.

Já o mês de dezembro representa o que detém a menor média pluviométrica do ano. Neste caso, não se verifica a potencialização da descarga dos coliformes através das águas pluviais e fluviais, diminuindo consideravelmente as contagens do NMP de coliformes, passando de 16.000 para 230 em junho no posto 4 e, de 5.000 para 900 no posto 8 .

Assim, ao considerar esses números para o mês de junho, a precipitação e, consequentemente, os afluxos pluviais e fluviais ganham reforço da influência das marés no adensamento dos coliformes nessas localizações pois, são as maiores responsáveis pela penetração das águas do oceano na laguna Mundaú.

De acordo com os relatórios da Segunda Campanha de Medições Hidráulico-Sedimentológicas no Complexo Lagunar Mundaú-Manguaba (PORTOBRÁS; INPH, 1985), as amplitudes de maré refletem a dificuldade de penetração da onda de maré já que o amortecimento causado pela embocadura reduz em $70 \%$ tal amplitude. Além disso, do restante que consegue transpor a barra há ainda uma redução de mais 50\%.

Nobre et al. (2000) afirmam que, apesar da dificuldade de penetração da onda de maré no Complexo Estuarino e Lagunar Mundaú-Manguaba (CELMM), as marés exercem mais influência na laguna Mundaú do que na Manguaba, mesmo nas porções mais interioranas, e isso se deve à facilidade de conexão hidráulica entre esta laguna e o oceano atlântico.

Vinculado a isso, a batimetria também contribui com o fenômeno estudado, uma vez que corresponde à fisiografia afogada do local, isto é, aos padrões de zonas profundas e rasas da área estudada; já que a lâmina d'água é menos espessa em algumas porções, propiciando, com isso, uma menor diluição dos afluentes fluviais e pluviais. 
Com isso, a laguna Mundaú apresenta, no entorno do posto $n^{\circ} .4$ (Canal da Levada), uma profundidade que varia de 0 a $1,0 \mathrm{~m}$, à medida que nas adjacências do posto $\mathrm{n}^{\circ} .8$ (Canal da Assembleia) a faixa batimétrica oscila entre 1,5 e 2,0 m (FRAGOSO JÚNIOR; SOUZA, 2003).

Outro fator preponderante na distribuição espacial da variável analisada diz respeito aos ventos, enquanto modelador da hidrodinâmica lagunar.

$\mathrm{Na}$ costa nordestina geralmente se apresentam no sentido Leste-Oeste. Eles são mais comumente conhecidos como ventos alísios. Rocha e Lyra (2000) afirmam que, por estar contido na estação chuvosa, o mês de junho apresenta, historicamente, uma redução da intensidade dos ventos. Isto se deve porque no inverno a diferença de temperatura oceanocontinente diminui, provocando uma atenuação da brisa marítima e, portanto, propiciando uma maior variabilidade na direção dos ventos.

Segundo Silva (2007) a velocidade dos ventos é maior nos meses mais quentes (Figura 5). Isto se dá por conta do aquecimento da superfície terrestre, o que aumenta a diferença de temperatura entre o oceano e a terra.

Figura 5 - Velocidade média dos ventos nos períodos de inverno e verão.

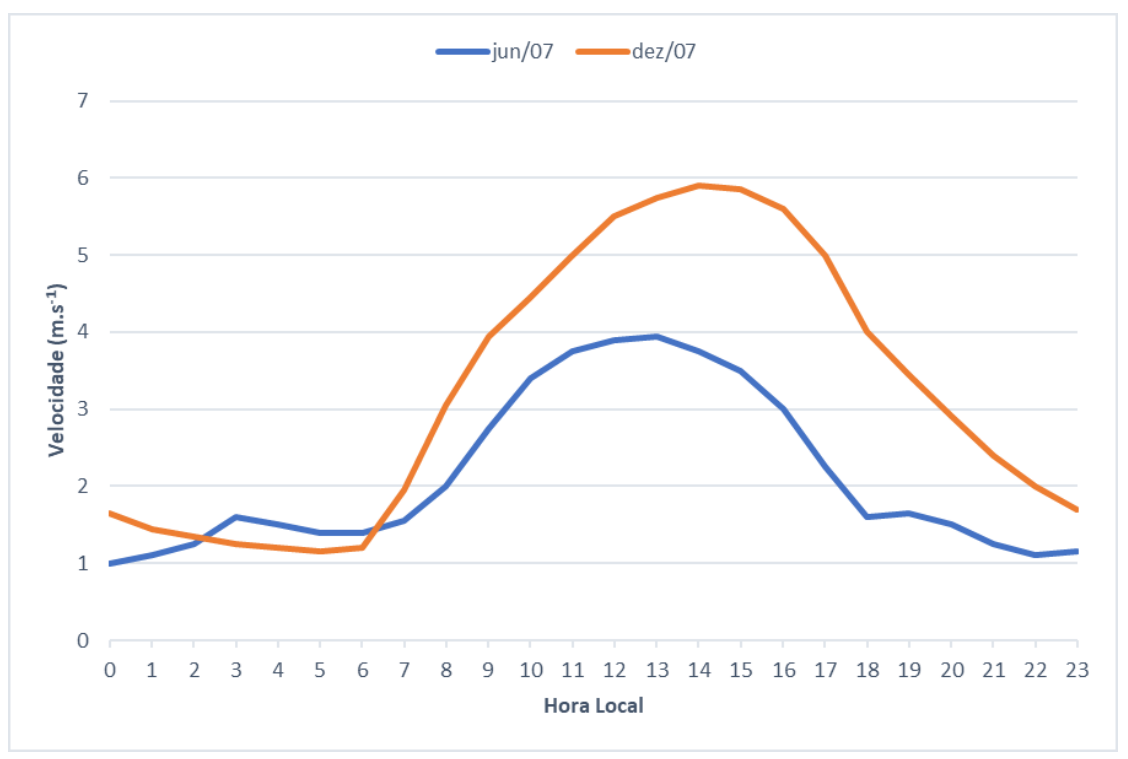

Fonte: Silva (2007).

A direção dos ventos também muda entre estas estações. Rocha e Lyra (2000) explicam que durante o inverno a temperatura oceânica diminui, atenuando a brisa marítima e, por isso, há uma maior variabilidade na direção dos ventos. Silva $(2007$; p. 29) complementa que durante o verão, com o aquecimento do ar e, consequentemente, da superfície terrestre, há uma provocação de

[...] movimentos convectivos, ou seja, movimentos ascendentes que leva o calor da superfície para a atmosfera e, com isso gera turbilhões no deslocamento do ar e consequentemente retardo no seu deslocamento horizontal.

Rocha e Lyra (2000) acrescentam ainda que, a costa alagoana se apresenta em um ângulo de aproximadamente $45^{\circ}$ levando em consideração o eixo Norte-Sul da terra e isso faz 
com que a brisa de terra-mar seja direcionada no sentido Sudeste-Noroeste, com maiores frequências diurnas de Leste no verão e de Sudeste no inverno e, noturnas, de Sul no verão e de Sudoeste no inverno (Figura 6).

Figura 6 - Direção predominante dos ventos diurnos e noturnos nas estações de inverno e verão.

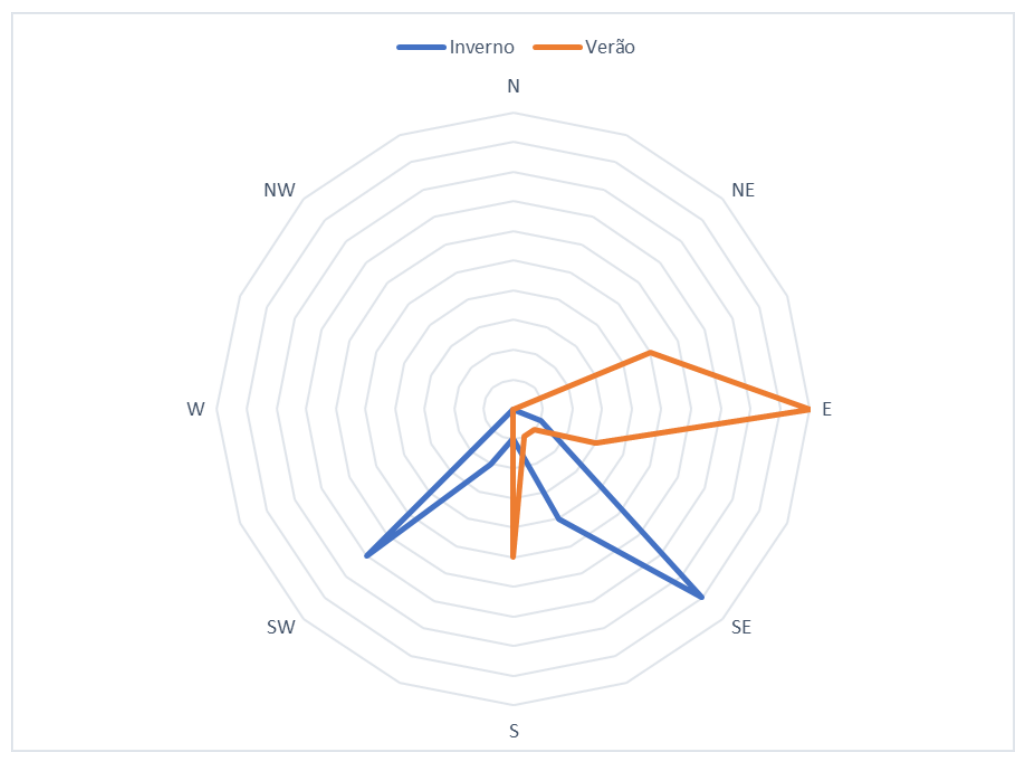

Fonte: Silva (2007).

A conjugação dos fatores anteriormente apresentados reúne, por si só, as condições propícias para concentração dos coliformes termotolerantes em determinados locais e, em outros, mais dispersos. Entretanto, não se pode desconsiderar o fator geomorfológico como corresponsável no fenômeno em questão.

$\mathrm{Na}$ localização em torno do posto $\mathrm{n}^{\circ} .4$, a forma do relevo se apresenta como uma espécie de baía ou enseada, dificultando a circulação da água nessas imediações. De forma geral, esta forma proporciona um confinamento mais prolongado da descarga de coliformes no período chuvoso porque o tanto o sentido quanto o fluxo das águas levam mais tempo para atingir essa localização, uma vez que as águas tendem a fluir entre a porção central da laguna e o canal de ligação com o oceano.

Por este motivo, a geomorfologia nas adjacências do posto $n^{\circ} .8$ proporciona uma maior dispersão ou deslocamento dos efluentes, não tratados, diluídos nas águas do canal, em função da constante troca de massas d'água estuarina.

\section{CONCLUSÕES}

De acordo com as resoluções CONAMA n . 274/2000 e 357/2005, a contaminação das águas, com coliformes, para o mês de junho, em quase toda a extensão da laguna, supera em aproximadamente 6,5 vezes o valor especificado pelas aludidas resoluções. Já as águas de dezembro foram consideradas satisfatórias para a balneabilidade e inadequada para o cultivo do sururu. 
Quanto a dispersão dos coliformes no interior da laguna Mundaú, o aporte de efluentes fluviais e pluviais, a amplitude das marés, a direção e a velocidade dos ventos, a batimetria e a geomorfologia influenciam significativamente, ora na renovação das águas, ora na sua retenção.

As interpolações realizadas por meio do software QGIS corresponderam satisfatoriamente à realidade do fenômeno estudado. O seu manuseio e a acurácia nas operações realizadas mostraram grande potencial desta ferramenta, não deixando nada a desejar em relação aos programas comerciais.

\section{REFERÊNCIAS}

ALAGOAS. Projeto de atualização dos conhecimentos e formulação de estratégias de manejo de lagoas costeiras para pesca e aquicultura. Estudo de caso: Complexo estuarino lagunar MundaúManguaba. Maceió: Instituto do Meio Ambiente de Alagoas, 1988. 75p.

ALAGOAS. Dados do monitoramento climático para o estado de Alagoas. Disponível em $<$ https://goo.gl/mBJybH>. Acesso em 03. jan. 2009.

BRASIL. Ministério da Saúde. Agência Nacional de Vigilância Sanitária. Resolução no 275 de 22 de Setembro de 2005. Regulamento Técnico de Características Microbiológicas para água Mineral Natural e Água Natural. Diário Oficial da União, Brasília, 23 de Setembro de 2005.

CORREIA, P. Modelação e estimação: uma introdução à geoestatística. Curitiba: Numist, 2010. 80 p.

FRAGOSO JÚNIOR, C. R.; SOUZA, C. F. Análise de uma proposta de dragagem no complexo estuarino lagunar Mundaú-Manguaba através de um modelo hidrodinâmico bidimensional. 2003. 151 f. TCC (Graduação) - Curso de Engenharia Civil, Centro de Tecnologia, Universidade Federal de Alagoas, Maceió, 2003.

LANDIM, P. M. B. Análise Estatística de Dados Geológicos. Fundação Editora da UNESP, São Paulo, 1998. 226 p.

LANDIM, P. M. B. Introdução aos métodos de estimação espacial para confecção de mapas. Rio Claro: UNESP, 2000. Disponível em: < https://goo.gl/zwu3zF > . Acesso em: 03.jan. 2009.

NOBRE, R. C. M. et al. Modelo de Circulação Hidrodinâmica Aplicado ao Complexo Estuarino Lagunar Mundaú-Manguaba. In: I CONGRESSO SOBRE APROVEITAMENTOS E GESTÃO DE RECURSOS HÍDRICOS EM PAÍSES DE IDIOMA PORTUGUÊS, 1., 2000, Rio de Janeiro. Anais... . Rio de Janeiro, 2000. p. 1 - 10.

OLEA, R. A. Geostatistical glossary and multilingual dictionary. Oxford University Press. New York, 1991. $177 \mathrm{p}$.

PORTOBRÁS; INPH. Relatório da primeira campanha de medições hidráulico-sedimentológicas no complexo lagunar Munaú-Manguaba. Rio de Janeiro: Empresa de Portos do Brasil S.A., Instituto Nacional de Pesquisas Hidroviárias, 1984. Vol. I e Vol. II. 249p.

PORTOBRÁS; INPH. Relatório da segunda campanha de medições hidráulico-sedimentológicas no complexo lagunar Munaú-Manguaba. Rio de Janeiro: Empresa de Portos do Brasil S.A., Instituto Nacional de Pesquisas Hidroviárias, 1985. Vol. I e Vol. II. 230p.

ROCHA, C. H. E.; LYRA, R. F. da F. Ocorrência de brisas na região de tabuleiros costeiros próximo a Maceió-AL. In: Congresso Brasileiro de Meteorologia, XI, A Meteorologia Brasileira Além do Ano 2000. Anais... Rio de Janeiro, 2000.

SILVA, J. K. A. da. Caracterização do vento e estimativa do potencial eólico para a região de tabuleiros costeiros (Pilar, Alagoas). 2007. 83 p. (MET-UFAL-MS/047). Dissertação (Mestrado em Meteorologia) Universidade Federal de Alagoas, Maceió. 2007.

VARELLA, C. A. A.; SENA JUNIOR, D. G. Estudo do interpolador IDW para utilização em agricultura de precisão. Seropédica, 2008. 26 p. 
VON SPERLING, M. Introdução à qualidade das águas e ao tratamento de esgotos. Editora UFMG, 2005.

WORLD HEALTH ORGANIZATION - WHO. Guidelines for drinking-water quality. Volume 1. Recommendations. WHO, Geneva. 2 ed. 188 p. 1993. 